\title{
A Mixed-Methods Inquiry into the Intimate Practices of Partnered Mature Students and Influences on Relationship, Sexual, and School Satisfaction
}

Tricia M. van Rhijn

University of Guelph

Sarah H. Murray

American Association of Marriage and Family Therapists

Robert C. Mizzi

University of Manitoba

\begin{abstract}
Through the use of mixed qualitative and quantitative methods, the current study explored the impact of postsecondary study on the intimate relationships and school experiences of partnered mature students. Quantitative regression analyses indicated that parental status, family support, partner support, and sexual desire significantly predicted relationship satisfaction, while family support and partner support significantly predicted sexual satisfaction. Age and sexual desire predicted school satisfaction for women only. Through qualitative thematic analysis it was determined that not having enough time, feeling too tired, and being stressed negatively impacted sexual satisfaction, while experiencing personal growth was described as both beneficial and problematic. Some participants reported using sex to aid in their academic success by way of offering a distraction or reducing stress. We discuss possible ways that postsecondary institutions, through their campus programs, can better address the impact school may have on mature students' intimate relationships.
\end{abstract}




\section{Résumé}

Grâce à l'utilisation d'une variété de méthodes qualitatives et quantitatives, l'étude suivante étudie l'effet des études post-secondaires sur les relations intimes et les expériences scolaires des étudiants adultes en couple. La régression des analyses quantitatives indique que le statut parental, le soutien familial, l'appui du partenaire et les désirs sexuels prédisent significativement la satisfaction à l'égard des relations personnelles, tandis que le soutien familial et l'appui du partenaire prédisent de façon significative la satisfaction sexuelle. L'âge prédit aussi la satisfaction académique chez les hommes et les femmes, de même que le désir sexuel chez les hommes seulement. En utilisant une analyse thématique qualitative, il a été déterminé que le fait de ne pas disposer d'assez de temps, la fatigue et le stress ont des répercussions négatives sur la satisfaction sexuelle. Enfin, une croissance personnelle a été décrite comme étant à la fois bénéfique et problématique. Certains participants ont déclaré avoir utilisé le sexe pour aider à leurs réussites scolaires afin de s'offrir une distraction ou de diminuer leur stress. Nous discutons des moyens possibles pour les institutions post-secondaires de mieux traiter, par le truchement de leurs programmes, l'effet que peuvent avoir les études sur les relations intimes des étudiants adultes.

University campuses have increasingly become responsible for, and responsive to, students' sexuality-related issues. For example, many campuses now have sexual health seminars and/or centres to communicate helpful information to the student body about maintaining a healthy sexual life. In addition, university administrations on many campuses have investigated and addressed sexual harassment and violence to end and prevent such encounters (e.g., Best, Smith, Raymond, Green, \& Crouch, 2010). In both cases, students are dependent on higher education institutions for sexual information, safety, and recovery. While ad hoc curricula and practices, such as workshops on sexual health and safety, are important tools, an integrated and holistic approach to sexuality and relationships in the university setting may improve students' experiences and learning outcomes. Further, because the majority (65\%) of university students fall between the ages of 18 and 24 (Statistics Canada, 2013), sexual health centres may be prone to focusing on sexuality issues that are age and demographic specific (e.g., safety around casual sexual encounters) and may not adequately address experiences of mature students (e.g., sexuality and intimacy in the context of longer-term relationships).

Mature students, whom we define as undergraduate students aged 25 and older, are considered to face unique challenges as non-traditional students. These challenges typically relate to the difficulties they face when combining school and family roles and responsibilities (e.g., Carney-Crompton \& Tan, 2002; Giancola, Grawitch, \& Borchert, 2009; Home, 1997, 1998; Kirby, Biever, Martinez, \& Gomez, 2004; Quimby \& O’Brien, 2006; Sweet \& Moen, 2007). Home (1997) notes that "combining higher education and family is especially problematic, as both are 'greedy' institutions that demand exclusive loyalty, virtually unlimited time commitments, and high flexibility" (p. 336). This means that, as a result of being older than traditional postsecondary students, mature students generally experience heightened and complex financial and familial responsibilities beyond those of their traditional-aged peers, which may explain the rise in divorce rates 
among partnered mature students during and after the return to school (Galvin, 2006). Furthermore, the interaction between intimate relationships and academic pursuits may be bidirectional in nature. A better understanding of the nature of this changing relationship forms the impetus of this current study.

Returning to school (i.e., a formal education setting such as university) can be a stressful experience for mature students, and the strains from school demands may influence the quality and quantity of time they spend with their romantic partner (Giancola et al., 2009; Gold, 2006). For example, in Giancola and colleagues' (2009) study of transferred stress between work, school, and family among mature students, the researchers found that participants experienced the greatest conflict from school demands that negatively impacted their family. In addition, Gold's (2006) study on the topic of mature graduate students found that the stresses related to higher education (including financial strains and having less "free time" to be at home with their partners) negatively impacted their satisfaction within their intimate relationships.

Conversely, it may be that the quality of mature students' intimate relationships influences their academic success. It has been documented that the degree to which an individual is satisfied in their sexual and intimate relationship has a significant positive impact on their quality of life (Chao et al., 2011) and overall well-being (Lawrance \& Byers, 1998). Specifically, individuals reporting instability in their relational and sexual satisfaction are more likely to experience depression (Whitton \& Whisman, 2010) and stress (Røsand, Slinning, Eberhard-Gran, Røysamb, \& Tambs, 2012). In contrast, individuals who report higher relationship satisfaction are found to experience a buffer against external strains and stressors (Kirby et al., 2004; Røsand et al., 2012). Therefore, the factors that are regularly found to negatively impact student learning (i.e., stress and depression; Yousefi, Mansor, Juhari, Redzuan, \& Talib, 2010) may be mediated by facets of the students' romantic lives, such as the quality of their relationships with intimate partners.

This study is situated within the work-family literature, with a focus on multiple roles. Earlier interpretations of Role Theory focused on the "scarcity hypothesis" (Goode, 1960), which suggests that strain and conflict are the result of engaging in too many or overly demanding roles. Therefore, additional roles and demands increase the likelihood of negative outcomes (e.g., stress; Mullen, Kelley, \& Kelloway, 2008). This negative relationship between multiple roles is referred to as work-family conflict, defined by Greenhaus and Beutell (1985) as a form of conflict between work and family roles, resulting from incompatible demands. More recently, the focus has been turned to the benefits that can accrue from engaging in multiple roles. These benefits are referred to as work-family enrichment, defined by Greenhaus and Powell as the "extent to which experiences in one role improve the quality of life in the other role" (2006, p. 73). Van Rhijn adapted these concepts to include school and family roles (2009), due to their applicability to the lives of mature students-student parents in particular. More recent work by van Rhijn (2012) highlights the particular importance of partners in the lives of mature students in university both as motivators to continue attending school and as sources of social support.

A focus on multiple roles was used to guide this study, as mature students have chosen to become students, a voluntary role that they often take on in addition to family and work roles. Given institutions' focus on student success (i.e., retention, program completion), if one adds this demanding pressure to the desire to succeed in the family context (i.e., by doing a good job as a partner or parent), there are likely to be negative impacts 
on role-related performance, due to increased experiences of role conflict in the form of time-based and strain/stress-based demands. The work-family literature provides evidence that multiple roles are beneficial for both men and women, yet these benefits can be attenuated when too many roles are taken on or the demands from one particular role are excessive (Barnett, 2008).

Through the use of mixed qualitative and quantitative methods, this study aimed to open a discussion that has yet to be explored in the literature, in order to begin a process of considering intimate relationships as a way to enhance mature students' experiences in their school and family roles. With the expanding focus on mature students in both practice and policy among postsecondary institutions across Canada and elsewhere, this project is both timely and urgent in order for campuses to reflect inclusiveness, comprehensiveness, and sensitivity to mature students and their relationship needs. Specifically, the preliminary objective of this research was to address the following question: How does participation at university impact relationship quality for mature students?

\section{Methods}

Data for this study were collected using an online survey instrument with a mix of open- and closed-ended questions during the fall 2012 phase of a three-year study of mature students, the Mature Student Experience Survey (MSES). Mature students were recruited with assistance from registrars' offices at four universities in southern Ontario. In addition to being a mature student, participants for this study were required to be partnered (i.e., married to or living with a partner) so that participants were better able to reflect on their life circumstances in relation to the study topic as they completed the survey. A sample of 528 mature students was obtained for this study.

\section{Measures}

The measures included the following demographic variables: age, gender, parental status, immigration status, sexual orientation, partner status, and full- or part-time study designation. Descriptive statistics and zero-order correlations among the measures are provided in Table 1. With the exception of desire for men and school satisfaction, significant positive correlations were found among the measures, and the internal consistency coefficients (Cronbach's alpha) ranged from .89 to .96.

Change in frequency. To provide an overall assessment of changes in intimate relations and sexual activity, the researchers created two items: (i) "Since the semester began how has the frequency of sexual activity (e.g., penile-vaginal penetration, oral sex, handgenital stimulation) with your partner changed?" and (ii) "Since the semester began how has the frequency of intimate relations (e.g., cuddling, caressing) with your partner changed?" Three response options were provided: "no change," "increased," and "decreased."

Desire. Desire was measured using the desire subscales from the Female Sexual Function Index (FSFI; Rosen et al., 2000) and the Brief Male Sexual Function Inventory (BMSFI; O'Leary et al., 1995). Both subscales are self-report measures regarding sexual desire over the past month. Each subscale has two items, with the response options varying for each item. Higher scores indicate higher reported sexual desire. A sample item from the FSFI is "Over the past 4 weeks, how often did you feel sexual desire or interest?" A sample item from the BMSFI is "During the past 30 days, on how many days have you felt sexual drive?" 
Table 1.

Descriptive Statistics and Zero-Order Correlations of Study Variables

\begin{tabular}{|c|c|c|c|c|c|c|c|}
\hline & 1 & 2 & 3 & 4 & 5 & 6 & 7 \\
\hline Desire (females only) & - & & & & & & \\
\hline Desire (males only) & $.83^{* * *}$ & - & & & & & \\
\hline Family support & $.24^{* * *}$ & $.19^{* *}$ & - & & & & \\
\hline Partner support & $.20^{* * *}$ & $.27^{* * *}$ & $.50^{* * *}$ & - & & & \\
\hline Relationship satisfaction & $.30^{* * * *}$ & $.30^{* * *}$ & $.52^{* * *}$ & $.54^{* * *}$ & - & & \\
\hline Sexual satisfaction & $.48^{* * * *}$ & $.36^{* * *}$ & $.42^{* * *}$ & $.39^{* * *}$ & $.66^{* * *}$ & - & \\
\hline School satisfaction & $.12^{*}$ & .10 & $.15^{* *}$ & $.10^{*}$ & $.14^{* *}$ & $.16^{* * *}$ & - \\
\hline$M$ & 3.45 & 4.22 & 20.01 & $7 \cdot 71$ & 29.74 & 26.76 & 26.79 \\
\hline$S D$ & 1.24 & 1.95 & 4.09 & 2.48 & 5.61 & 7.70 & 5.58 \\
\hline Cronbach's a & .92 & .89 & .89 & - & .93 & .96 & .89 \\
\hline
\end{tabular}

$* p<.05 . * * p<.01 . * * * p .001$.

Family and partner support. Family support was measured using a five-item scale modified from the National Study of the Changing Workforce, by Sweet and Moen (2007). Responses are measured using a five-point scale ( $1=$ "never" and $5=$ "always") indicating the degree to which an individual is satisfied with the support he or she receives from family members. A sample item is "You are satisfied that you can turn to your family for help when something is troubling you." Partner support was measured in response to a single item: "Using a scale of $\mathrm{o}$ to 10 , where $\mathrm{o}=$ not at all willing and $10=$ extremely willing, how willing is your (spouse/partner) to help you out at home after a very demanding day?"

Relationship and sexual satisfaction. Relationship and sexual satisfaction were measured using the Global Measure of Relationship Satisfaction and the Global Measure of Sexual Satisfaction (GMREL \& GMSEX; Lawrance \& Byers, 1998). Responses are assessed using the following five bipolar scales (scores on each range from 1 to 7 ): bad-good, unpleasant-pleasant, unsatisfying-satisfying, negative-positive, and worthless-valuable. The scales measure global satisfaction with the overall relationship (GMREL) and sexual relationship (GMSEX).

School satisfaction. School satisfaction was measured using the five-item school subscale of the Extended Satisfaction with Life Scale (Alfonso, Allison, Rader, \& Gorman, 1996). Responses are measured using a seven-point Likert scale ( 1 = "strongly disagree" and 7 = "strongly agree"), with higher scores indicating higher levels of satisfaction. A sample item is "The education I get at school is great."

Open-ended question. In addition to the measures, the following open-ended question was included in the survey: "Please describe how attending school has contributed to changes in your experience of sexual satisfaction, desire, sexual activity, or intimate relations."

\section{Analytic Strategy}

An exploratory mixed-methods approach to data analysis was utilized that involved collection and analysis of both quantitative and qualitative data; specifically, the current 
investigation utilized a mixed-methods concurrent triangulation design (Creswell, Plano Clark, Gutmann, \& Hanson, 2003), whereby the data were collected at the same point in time and both qualitative and quantitative methods were used for analysis. A mixedmethods approach to the research provided us with more comprehensive evidence for this study than either a quantitative or a qualitative approach alone (Creswell \& Plano Clark, 2007). The quantitative analysis allowed us to examine how relationship satisfaction, sexual satisfaction, and school satisfaction relate to desire and family/partner support for mature students. The qualitative analysis afforded us the opportunity to explore the relationship between school attendance and intimate relations more deeply, and the possibility to explain and/or build on the quantitative findings.

\section{Results}

Participants were 528 mature students attending university in Canada, with a large majority ( $n=518,98.1 \%)$ attending one of four Ontario institutions at which recruitment efforts occurred. Participants were required to be in a committed same-sex or cross-sex partner relationship, currently living with a partner and attending university on either a full- or part-time basis. A majority of participants identified as heterosexual $(89.7 \%, n$ $=462)$ with only $4.5 \%(n=23)$ identifying as gay or lesbian, 3.1\% $(n=16)$ identifying as bisexual, and the remaining 2.7\% $(n=13)$ identifying as another sexual orientation (e.g., questioning, queer, two-spirit, or other). There were 372 women participants, ranging in age from 24 to 76, and 154 men participants, ranging in age from 25 to 80 (Table 2). The majority of the participants had been born in Canada (60.6\%), and almost half had dependent children living with them (46.6\%). Men and women were not significantly different for age or parental status; however, women were significantly more likely to be Canadian-born and significantly less likely to be studying on a full-time basis.

Table 2.

Sample Characteristics

\begin{tabular}{|c|c|c|c|c|c|c|c|c|c|}
\hline & \multicolumn{3}{|c|}{ Total $(N=528)$} & \multicolumn{3}{|c|}{$\operatorname{Men}(n=154)$} & \multicolumn{3}{|c|}{ Women $(n=372)$} \\
\hline & \multicolumn{3}{|c|}{ Mean/ } & \multicolumn{3}{|c|}{ Mean/ } & \multicolumn{3}{|c|}{ Mean/ } \\
\hline & $n$ & $\%$ & SD & $n$ & $\%$ & SD & $n$ & $\%$ & $\mathrm{SD}$ \\
\hline Age & 527 & 37.2 & 10.1 & 153 & 38.2 & 10.5 & 372 & 36.8 & 10.0 \\
\hline Born in Canada & 215 & 60.6 & & 50 & 51.0 & & 165 & $64.2 *$ & \\
\hline Dependent child ${ }^{a}$ & 245 & 46.6 & & 70 & 45.5 & & 175 & 47.0 & \\
\hline Studying full-time ${ }^{b}$ & 245 & 46.8 & & 85 & 55.2 & & 160 & 43.4 & \\
\hline
\end{tabular}

${ }^{*} p<.05 .{ }^{* *} p<.01 .{ }^{* * *} p<.001$.

Note. Significance tests were conducted as follows: Independent samples $t$ tests were used for continuous variables, and Pearson chi-square difference tests were used for categorical variables.

a Participants had at least one dependent child under the age of 18 living with them.

${ }^{\mathrm{b}}$ Full-time status was defined according to Canada Student Loans Program requirements of 60\% or greater of a full course load. 
There were preliminary indications of the impact of school attendance on intimacy and sexuality. Participants were asked how the frequency of both intimate relations and sexual activity with their partner had changed since the beginning of the semester. A majority of participants indicated that there was no change in either their intimate relations or their sexual activity (62.0\% and $55.4 \%$, respectively). The largest change was to the frequency of sexual activity, with $41.3 \%$ of participants reporting a decrease. For intimate relations, $29.2 \%$ of participants reported a decrease in frequency. Only a small minority of participants reported an increase in sexual activity (3.3\%) and intimate relations (8.8\%). No significant differences were found between men and women for either of the frequency questions.

\section{Quantitative Results}

For the quantitative analysis, we conducted three hierarchical multiple regressions, with relationship satisfaction, sexual satisfaction, and school satisfaction as the dependent (outcome) variables. Age, parental status, and sexual orientation were included as covariates (control variables) in the first block (Model 1). The second block (Model 2) added enrolment status (full- or part-time study), family support, partner support, and desire. The three models were run separately for each gender for two reasons: (i) because the desire scales were unique for men and women, and (ii) to allow comparison of the results for men and women.

The regression results pertaining to relationship satisfaction are presented in Table 3 . For men, the initial model was not significant, accounting for only $3 \%$ of the variance, $F(3,138)=1.13, p=.34, R^{2}=.03$. Adding the second block of variables, the second model accounted for a total of $41 \%$ of the variance in relationship satisfaction, $F(6,138)=12.79$, $p<.001, R^{2}=.41, \Delta R^{2}=.38$. Parental status, family support, partner support, and sexual desire were significant contributors to the variance in relationship satisfaction for men. For women, the initial model was significant and accounted for nine percent of the variance, $F(3,333)=11.01, p<.001, R^{2}=.09$. The second model accounted for an additional $37 \%$ of the variance in relationship satisfaction, $F(6,333)=40.02, p<.001, R^{2}=.46, \Delta R^{2}$ $=.37$. Significant contributors to the variance in relationship satisfaction for women were the same as for men (parental status, family support, partner support, and sexual desire), along with the addition of age.

The regression results pertaining to sexual satisfaction are presented in Table 4. For men, the initial model was not significant, accounting for only three percent of the variance, $F(3,135)=1.15, p=.33, R^{2}=.03$. After the addition of the second block of variables, the second model accounted for a total of $30 \%$ of the variance in sexual satisfaction, $F(6$, $135)=7.90, p<.001, R^{2}=.30, \Delta R^{2}=.28$. Significant contributors to the variance in sexual satisfaction for men included family support and partner support. The initial model was significant for women and accounted for three percent of the variance, $F(3,323)=$ $3.30, p=.02, R^{2}=.03$. The second model accounted for an additional $37 \%$ of the variance in sexual satisfaction, $F(6,323)=29.66, p<.001, R^{2}=.40, \Delta R^{2}=.37$. For women, significant contributors to the variance in sexual satisfaction included family support and partner support (as for men) as well as sexual desire. 
Table 3 .

Hierarchical Regression Results for Variables Predicting Relationship Satisfaction of Mature Students

\begin{tabular}{lcccccc}
\hline & \multicolumn{3}{c}{ Men $(n=154)$} & \multicolumn{3}{c}{ Women $(n=372)$} \\
\cline { 2 - 7 } Variable & $B$ & $S E$ & $\beta$ & $B$ & $S E$ & $\beta$ \\
\hline Model 1 & & & & & & \\
$\quad$ Age & -.06 & .04 & -.12 & -.07 & .03 & $-.11^{*}$ \\
$\quad$ Parental status & .73 & .92 & .07 & 2.54 & .63 & $.22^{* * *}$ \\
$\quad$ Sexual orientation & .12 & .56 & .02 & .39 & .23 & .09 \\
Model 2 & & & & & & \\
Age & -.03 & .04 & -.05 & -.06 & .03 & $-.09^{*}$ \\
Parental status & 1.53 & .74 & $.15^{*}$ & 1.53 & .50 & $.14^{* *}$ \\
Sexual orientation & .11 & .45 & .02 & .25 & .18 & .06 \\
Enrolment status & -.02 & .73 & -.00 & -.16 & .49 & -.01 \\
$\quad$ Family support & .40 & .09 & $.35^{* * *}$ & .43 & .07 & $.30^{* * *}$ \\
Partner support & .77 & .18 & $.33^{* * *}$ & .78 & .11 & $.35^{* * *}$ \\
Sexual desire & .41 & .20 & $.15^{*}$ & .65 & .21 & $.13^{* *}$ \\
\hline
\end{tabular}

${ }^{*} p<.05 .{ }^{* *} p<.01 .{ }^{* * *} p<.001$.

Men: Model 1, $F(3,138)=1.13, p=.34, R^{2}=.03$; Model 2, $F(6,138)=12.79, p<.001, R^{2}=.41, \Delta R^{2}=.38$

Women: Model 1, $F(3,333)=11.01, p<.001, R^{2}=.09 ;$ Model $2, F(6,333)=40.02, p<.001, R^{2}=.46, \Delta R^{2}=.37$

Table 4.

Hierarchical Regression Results for Variables Predicting Sexual Satisfaction of Mature Students

\begin{tabular}{lrrrrrr}
\hline & \multicolumn{3}{c}{ Men $(n=154)$} & \multicolumn{3}{c}{ Women $(n=372)$} \\
\cline { 2 - 7 } Variable & $B$ & $S E$ & $\beta$ & $B$ & $S E$ & $\beta$ \\
\hline Model 1 & & & & & & \\
$\quad$ Age & -.00 & .07 & -.00 & -.08 & .05 & -.09 \\
$\quad$ Parental status & -.05 & 1.35 & -.00 & 1.90 & .92 & $.12^{*}$ \\
$\quad$ Sexual orientation & -1.47 & .80 & -.16 & .12 & .35 & .02 \\
Model 2 & & & & & & \\
$\quad$ Age & -.03 & .06 & -.04 & -.07 & .04 & -.08 \\
Parental status & .67 & 1.17 & .05 & .44 & .74 & .03 \\
Sexual orientation & -1.35 & .69 & -.15 & -.07 & .28 & -.01 \\
$\quad$ Enrolment status & 1.17 & 1.14 & .08 & 1.19 & .73 & .08 \\
$\quad$ Family support & .45 & .15 & $.25^{* *}$ & .46 & .10 & $.23^{* * *}$ \\
$\quad$ Partner support & 1.10 & .31 & $.31^{* * *}$ & .57 & .16 & $.19^{* * *}$ \\
Sexual desire & .59 & .31 & .14 & 2.7 & .31 & $.40^{* * *}$ \\
\hline
\end{tabular}

${ }^{*} p<.05 .{ }^{* *} p<.01 .{ }^{* * *} p<.001$.

Men: Model 1, $F(3,135)=1.15, p=.33, R^{2}=.03$; Model 2, $F(6,135)=7.90, p<.001, R^{2}=.30, \Delta R^{2}=.28$

Women: Model 1, $F(3,323)=3.30, p=.02, R^{2}=.03$; Model 2, $F(6,323)=29.66, p<.001, R^{2}=.40, \Delta R^{2}=.37$ 
The regression results pertaining to school satisfaction are presented in Table 5. The initial model was significant for men and accounted for $10 \%$ of the variance in school satisfaction, $F(3,144)=4.92, p=.003, R^{2}=.10$. The second model accounted for an additional $17 \%$ of the variance in school satisfaction, $F(6,144)=3.96, p=.001, R^{2}=.17$, $\Delta R^{2}=.07$, with age and sexual desire as the only significant contributors. For women, the initial model was also significant but accounted for only two percent of the variance, $F(3$, $331)=2.73, p=.04, R^{2}=.02$. The addition of the second block of variables accounted for an additional four percent of the variance, $F(6,331)=2.93, p=.005, R^{2}=.06, \Delta R^{2}=.04$. The only significant contributor to the variance in school satisfaction for women was age.

Table 5

Hierarchical Regression Results for Variables Predicting School Satisfaction of Mature Students

\begin{tabular}{lrrrrrr}
\hline & \multicolumn{3}{c}{$\operatorname{Men}(n=154)$} & \multicolumn{3}{c}{ Women $(n=372)$} \\
\cline { 2 - 7 } Variable & $B$ & $S E$ & $\beta$ & $B$ & $S E$ & $\beta$ \\
\hline Model 1 & & & & & & \\
$\quad$ Age & .12 & .05 & $.21^{*}$ & .08 & .03 & $.14^{*}$ \\
$\quad$ Parental status & -2.22 & 1.05 & $-.18^{*}$ & -.46 & .62 & -.04 \\
$\quad$ Sexual orientation & -.04 & .66 &.- .01 & -.02 & .22 & -.00 \\
Model 2 & & & & & & \\
$\quad$ Age & .14 & .05 & $.25^{* *}$ & .10 & .03 & $.17^{* *}$ \\
$\quad$ Parental status & -1.89 & 1.03 & -.15 & -.72 & .62 & -.07 \\
$\quad$ Sexual orientation & .07 & .64 & .01 & -.04 & .22 & -.01 \\
Enrolment status & .07 & 1.04 & .01 & -.63 & .62 & -.06 \\
$\quad$ Family support & .20 & .13 & .14 & .12 & .09 & .09 \\
$\quad$ Partner support & .17 & .26 & .06 & .11 & .13 & .05 \\
$\quad$ Sexual desire & .64 & .28 & $.19^{*}$ & .50 & .26 & .11 \\
\hline
\end{tabular}

${ }^{*} p<.05 .{ }^{* *} p<.01 .{ }^{* * *} p<.001$.

Men: Model 1, $F(3,144)=4.92, p=.003, R^{2}=.10$; Model 2, $F(6,144)=3.96, p=.001, R^{2}=.17, \Delta R^{2}=.07$ Women: Model 1, $F(3,331)=2.73, p=.04, R^{2}=.02 ;$ Model 2, $F(6,331)=2.93, p=.005, R^{2}=.06, \Delta R^{2}=.04$

\section{Qualitative Results}

For the qualitative analysis, 311 participants (out of the original 528, 59\%) completed text responses for the specific open-ended question: "Please describe how attending school has contributed to changes in your experience of sexual satisfaction, desire, sexual activity, or intimate relations." Of those 311 participants, 57 reported that returning to school had had no impact on their intimate relationships and did not expand on their experiences (i.e., "no impact" or "not applicable"). The qualitative analysis focused on the 254 participants who provided an explanation of any impact of their academic life on their intimate relationships. Using Braun and Clark's (2006) steps for thematic analysis, the second author began the initial steps of analysis. This process included (i) familiarization with the data, (ii) generation of initial codes, and (iii) searching for and identifying themes. Upon the comple- 
tion of independent coding, the first and second authors engaged in collaborative coding, at which time they (iv) compared and reviewed themes, paying attention to similarities and differences, (v) defined and named themes, and (vi) produced the written report. The first and second author then created five themes that captured the mature students' accounts of the impact school had on their intimate relationships with their romantic partners. Specifically, those themes were (i) having less time and/or different amounts of time to spend with one's romantic partner, (ii) feeling too tired from school to engage in sexual activity, (iii) being too stressed and distracted by school demands to connect intimately with one's partner, (iv) experiencing personal growth from returning to school, and (v) seeing benefits of having sex that improved school performance.

\section{Having Less Time and/or Different Schedules}

A dominant theme reported by a majority of participants was that the adjustment to schoolwork, assignments, and study at times took precedence over spending intimate time with their partner. As one participant described, "There never seems to be time to complete my school commitments and to also spend quality time with my spouse. My spouse always takes a backseat to schoolwork these days" (Female, 51). Another participant specified that, while schoolwork did not impact her desire to connect intimately, the increasing amount of time spent away from her partner meant that the opportunities to have sex were less frequent: "Satisfaction, desire, etc. have all stayed the same, however frequency (especially during weekdays) does decrease during very busy times of the semester (exams, major projects due, etc.)" (Female, 40).

Some participants indicated that changes to their schedule since returning to school had negatively impacted their time for intimacy. Specifically, the change of hours required for schoolwork (e.g., sometimes staying up late or having an unpredictable schedule based on assignment due dates) made it complicated to spend time with a partner who was working "regular" work week hours. For example, one participant explained, "I just don't have any other time to get my schoolwork done and am not an early morning person that can get up at 5 am like my husband to get the work done" (Female, 47).

Notably, a couple of participants indicated that, while school demands were high, they worked with their partner to find different times to connect intimately and engage in sexual activity. One participant described moving their intimate time to the mornings, as that was when both of them were at home: "have to be more flexible with timing. More morning sex than evening at present" (Male, 40).

\section{Feeling Too Tired}

Activities related to attending school were often described by participants as an additional obligation after raising their children and/or continuing with their paid employment. Connected to the increased amount of time required for school-related activities, participants described that they often felt much too tired to engage in sexual activities. One participant described:

I'm in school on Tuesdays and Wednesdays-most often they are 19 hour days between awakening and sleeping, working a full day on Thursday and have Fri-Mon for committee work, church work and schoolwork. My poor hubby needs to initiate every move. (Female, 37) 
Other participants described that sexual activity required a certain level of energy that they simply did not have after a full day at school. One participant shared: "All I want to do after a school day is fall asleep. Okay, maybe read a non-school book, then fall asleep. I'm just so exhausted!" (Female, 37).

\section{Experiencing Increased Stress and Distractions}

In addition to the increased time mature students reported spending on their schoolwork, many indicated that school demands and deadlines were stressful and distracted them from thinking about sex and their intimate relationships even when they were able to spend time with their romantic partners. One participant stated: "I feel much more distracted and stressed now that I am back at school, so it is harder to concentrate on sex" (Female, 27). Another participant described the difficulty concentrating on sexual activity and connecting with his partner when school demands were predominant:

When I am busy with school, that is what is on my mind most of the time. Honestly, when my partner wants to be sexual with me, even if we proceed with intimate relations, my mind often wanders to school or the amount of work I have to do. Like "oh, this is going to take 30 minutes, but I should really be studying." I think that's just awful that I can't be in the moment with my partner. (Male, 33)

Similarly, another participant described that when she and her partner finally had the time to connect physically, she often found that her mind was focused on school, and she could not block out those thoughts in order to focus on connecting with her partner. However, when school demands decreased, desire also went back to what she was used to. She stated: "When we do engage in sexual activities, I often am preoccupied with school thoughts, making intercourse less enjoyable. Notably, our relationship seems to return to a 'normal' state when school finishes for the holidays or summer vacation" (Female, 32).

\section{Personal Growth from Returning to School}

Some participants described experiencing personal growth when returning to school at an advanced stage of life, which had both positive and negative impacts on their relationship. A few participants described viewing school as something "youthful." Feeling younger and more vitalized was described as having a positive impact on some participants' sexual desire. As one participant stated: "being back at university has made me feel younger, and that has increased my desire" (Male, 35). The feeling of being younger as a result of returning to school was also described as having a positive impact on overall sexual satisfaction. Another participant stated: "[I] feel younger somehow or more engaged and therefore want to share that with [my] spouse. This sharing leads to more sexual activity and more sexual satisfaction" (Female, 49). One participant described, more explicitly, how the content of the courses she was taking for her degree was particularly relevant to her relationship and had a positive impact on her sexuality:

I'm getting a degree in Sexuality, Marriage, and Family. Almost every week I have something new for us to try or something we should talk about and consider. It makes it hard for things to get boring or less intense in that regard. We are both 
very open and honest communicators so I anticipate that even after I'm finished with my degree we will endeavour to continue to grow in our sexuality together. (Female, 27)

In addition, some participants described experiencing deepening rifts in their relationship since returning to school, which revolved around emotional distancing from their partners. This was described as being associated with participants' learning more or taking a different direction in their lives that their partners did not support or did not fully understand. For example, one participant explained that as she was learning more through her higher education, she found she could not talk about her learning with her husband. As a result of not being able to connect with her husband on something important in her life, she described feeling lower sexual desire for him.

Correspondingly, another participant noted that her partner did not take her return to school and associated stresses seriously, which caused tension in their relationship and sex life. Again, a lack of understanding and connection around mature students' experiences at school were described as dampening sexual desire: "We sometimes challenge each other to who had the worst day which turns into a competition, with a loser and winner... I feel sometimes my partner doesn't take my school stress seriously so I turn down sexual advances as punishment" (Female, 32).

\section{Sex as a Distraction/Benefit}

The majority of participants in the current study indicated that their return to school was stressful, time consuming, and had a somewhat negative impact on their relationship. However, there was a smaller group of participants who identified a positive relationship between their sex lives and school performance. Some participants described using sex as a way to reduce stress at school. One stated: "Sex can be a great de-stressor. Takes your mind away from other issues (school related) and reconnects me to my husband" (Female, 34). Others described using their sex life as a distraction or respite from school and their assignments. One stated: "when I have an assignment due, you KNOW I'm having sex to further my procrastination skills :)" (Female, 27). A third participant indicated that having sex helped with being able to fall asleep when the other stresses of school had built up: "Makes me want to have more sex. Helps to make me tired so I can fall asleep faster. But I still wake up my mind racing, making lists in my mind about all the stuff I have to do" (Female, 34).

Other participants described a more complicated relationship between school stress and sex. For example, the following participant described that the impact depended on the degree to which she was stressed. When her stress was very high, sex felt like another chore on top of her already long list of demands; however, when stress was less intense, sex could be a helpful way to relax:

Sometimes when really stressed I don't want to even think about satisfying my partner because it seems like too much work on top of the stress of school. But also sometimes sex can be a stress reliever but only when I'm moderately stressed-if very stressed then it just seems to add to my stress. (Female, 30) 


\section{Discussion}

The purpose of the current study was to explore the impact that attending university might have on mature students' intimate relationships, using a mixed-methods approach. The quantitative regression analyses indicated that parental status, family support, partner support, and sexual desire significantly predicted relationship satisfaction, while family support and partner support significantly predicted sexual satisfaction. The school involvement measure was not found to be influential in predicting relationship satisfaction, sexual satisfaction, or school satisfaction in this study. Age predicted school satisfaction with the addition of sexual desire for men only. The qualitative analysis provided a deeper exploration regarding the ways that returning to school impacted mature students' sexual and intimate relationships. Specifically, it was determined that not having enough time, feeling too tired, and being stressed negatively impacted sexual satisfaction, while experiencing personal growth was described as both beneficial and problematic. Some participants reported using sex as a way to aid in their academic success, such as by being a mechanism for coping with school stress.

Despite the minimal amount of research conducted on mature students and their intimate and sexual relationships, some findings from this study are consistent with past sexuality research in other populations. In a study of reasons to which women attributed their sexual problems in the United States, Ellison and Zilbergeld found that two of the three most common explanations included "being too tired" and "not having enough time" (as cited in Ellison, 2001). Similarly, in a qualitative study of emerging adult women it was reported that feeling stressed could reduce sexual desire for some women (Murray \& Milhausen, 2012). The research into men's sexual desire and arousal is dismal overall (Brotto, 2010); however, one study of men's sexual arousal suggests that stress can either inhibit or increase sexual desire, depending on the "level" of stress experienced (Janssen, McBride, Yarber, Hill, \& Butler, 2008). Being "too tired," "not having enough time" to have sex, and feeling "stressed" were the most commonly reported experiences provided by mature students in this study. These experiences are all forms of role conflict stemming from the school role and impacting the family role of the participants. The conflicts are from primarily time-based and strain-based demands, which have direct relationships to experiences of work-to-family conflict (Voydanoff, 2005). These conflicts, as described by Voydanoff, are similar to the school-to-family conflicts experienced by the mature students in this study. Given that the process of returning to school inevitably includes these conflicts and challenges, mature students may benefit from having an increased awareness of these changes when returning to school and from gaining access to supports when engaging in this transition.

This study is of significance to higher education, especially in relation to how previous work on mature students has suggested that social support is related to reductions in experiences of work-family conflict (e.g., Bernas \& Major, 2000; Michel, Kotrba, Mitchelson, Clark, \& Baltes, 2011). Sweet and Moen (2007) also demonstrated the relationship between declines in marital satisfaction related to a lack of instrumental support from partners. The findings from this particular study echo Sweet and Moen's results. More specifically, the qualitative results demonstrate how intimate and sexual relations with partners were impacted by fatigue, lack of time, and stress. The quantitative results demonstrate the importance of perceived support from family and partners for mature stu- 
dents' partner relationships. The mature students' experiences of role conflicts between their school and partner roles may be alleviated through the provision of support. Support may come in the form of preparing for the changes in intimate lives and developing negotiation strategies to maintain balance. We observed that study participants had had to renegotiate their intimate relationships in addition to other aspects of their roles (e.g., being a parent, student, worker), and that this renegotiation process had been largely unforeseen, circumstantial, and dependent on external conditions, which largely were coursework, compromises by partners, and complementary calendars. This observation suggests that complex and interconnected relationships exist between school, family, and work roles, and that returning to school as a mature student may have consequences that reshape intimate relationship dynamics. At times, mature students may experience role conflicts and struggle with meeting the needs and responsibilities familiar with each of these roles. Furthermore, our findings suggest that attending school-and the resulting personal growth and development that occurs-impacts individual identity, which can then impact partner relations both positively and negatively. We recommend that future work explore how changes in identity relate to changes in partner relationships.

\section{Limitations and Future Research Considerations}

Although this study provided some useful preliminary findings with regards to investigating the impact of mature students' return to school on their intimate relationship, we have identified five limitations in this study. First, the regression models predicting school satisfaction were only able to explain a small amount of variance, in particular for women. This finding suggests that further investigation of the factors influencing school satisfaction is required. In addition, it may be that a different dependent variable should be investigated, such as intention to leave study, or some measure of academic success (e.g., grades, course completion).

Second, the inclusion of sexual orientation as a covariate failed to significantly contribute to any of the regression models. This finding should not be interpreted to mean that sexual orientation has no influence; rather, the small proportion of participants in our sample identifying with a sexual orientation other than heterosexual limited the ability of the analysis to detect any significant differences.

Third, we have made the assumption that sex and intimacy with partners is a positive practice (i.e., it contributes to enhanced satisfaction and well-being) and that frequency is one indicator of sexual and relationship satisfaction. We recognize that individuals have varying perspectives regarding the importance of sex and intimacy to their relationship and that further qualitative work is required to examine this unique context.

Fourth, we only focused on the students' perceptions of the impact that attending school had on their relationships; future work is required to investigate the impact, including pre-post measures of relationship quality and a control group.

Fifth, the inclusion criteria restricted our ability to investigate those in other relationships who did not fit within the inclusion criteria (e.g., partners not living together, those in polyamorous relationships, individuals in uncommitted relationships). Qualitative interviews that explore this experience in more depth-allowing for a broader definition of partner relations, researching both student and partner perspectives, and addressing reasons that negate this impact-would be of value for future work. 
One additional point about this study is that, in addition to the explanations mature students gave regarding how returning to school had impacted their relationships (including their sexual lives), some participants also took the opportunity to express other sexual concerns (i.e., experiences of sexual abuse or sexual dysfunctions), as well as lesbian, gay male, and bisexual perspectives on being a mature student. These other perspectives were considered separate from their return to school and were not reflected in our current analysis.

\section{Implications and Concluding Thoughts}

This study and its findings suggest that there are connections between mature students' pursuit of higher education and their maintenance of intimate relationships. Accordingly, consideration of mature students' intimate relationships might be helpful in improving student learning outcomes and experience. Unlike race, class, citizenship, and gender, intimate relationships are largely ignored in the literature on the school experiences of mature students. Partnered mature students in this study experienced conflicts between their multiple roles, in particular those at school and at home, from incompatible demands and role responsibilities. There was also some evidence that mature students experienced some enrichment from their additional student role that carried over into their partner relationship. These findings support the use of a role theory lens when investigating the experiences of this particular student population; in particular, the experiences of partnered mature students beyond their student role should not be ignored. Our findings suggest that university policymakers and program leaders include consideration of partner relationships when creating and adapting supports and resources to meet the needs of mature students, in light of challenges around maintaining intimate relationships and the potential positive impact of partner support on school-related success. As mature students continue to be a significant population on Canadian campuses and potentially a growing population, especially during challenging financial times (e.g., van Rhijn, Smit Quosai, \& Lero, 2011), so does the need to effectively address their concerns in order to retain them as students throughout their academic programs. Supporting and retaining mature students may mean "breaking the silence" on often ignored topics, such as close relationships, intimacy, and sexuality.

\section{References}

Alfonso, V. C., Allison, D. B., Rader, D. E., \& Gorman, B. S. (1996). The Extended Satisfaction With Life Scale: Development and psychometric properties. Social Indicators Research, 38(3), 275-301.

Barnett, R. C. (2008). On multiple roles: Past, present, and future. In K. Korabik, D. S. Lero, \& D. L. Whitehead (Eds.), Handbook of work-family integration: Research, theory, and best practices (pp. 75-93). San Diego, CA: Elsevier.

Bernas, K. H., \& Major, D. A. (2000). Contributors to stress resistance: Testing a model of women's work-family conflict. Psychology of Women Quarterly, 24(2), 170-178.

Best, C. L., Smith, D. W., Raymond, J. R., Greenberg, R. S., \& Crouch, R. K. (2010). Preventing and responding to complaints of sexual harassment in an academic health center: A 10-year review from the Medical University of South Carolina. Academic Medicine, 85(4), 721-727. 
Braun, V., \& Clarke, V. (2006). Using thematic analysis in psychology. Qualitative Research in Psychology, 3, 77-101. doi:10.1191/1478088706qpo63oa

Brotto, L. (2010b). The DSM diagnostic criteria for hypoactive sexual desire disorder in men. Journal of Sexual Medicine, 7, 2015-2030. doi: 10.1111/j.1743-6109.2010.01860.x

Carney-Crompton, S., \& Tan, J. (2002). Support systems, psychological functioning, and academic performance of nontraditional female students. Adult Education Quarterly, 52(2), 140-154. doi:10.1177/0741713602052002005

Chao, J.-K., Lin, Y.-C., Ma, M.-C., Lai, C.-J., Ku, Y.-C., Kuo, W.-H., \& Chao, I.-C. (2011). Relationship among sexual desire, sexual satisfaction, and quality of life in middle-aged and older adults. Journal of Sex and Marital Therapy, 37, 386-403. doi:10.1080/0092 623X.2011.607051

Creswell, J. W., \& Plano Clark, V. L. (2007). Designing and conducting mixed methods research. Thousand Oaks, CA: Sage.

Creswell, J. W., Plano Clark, V. L., Gutmann, M. L., \& Hanson, W. E. (2003). Advanced mixed methods research designs. In A. Tashakkori \& C. Teddlie (Eds.), Handbook of mixed methods in social and behavioral research (pp. 209-240). Thousand Oaks, CA: Sage.

Ellison, C. R. (2001). A research inquiry into some American women's sexual concerns and problems. In E. Kaschak \& L. Tiefer (Eds.), A new view of women's sexual problems (pp. 147-160). Binghamton, NY: Haworth Press.

Galvin, C. R. (2006). Research on divorce among postsecondary students: Surprisingly missing. The Family Journal, 14(4), 420-423. doi:10.1177/1066480706291041

Giancola, J. K., Grawitch, M. J., \& Borchert, D. (2009). Dealing with the stress of college: A model for adult students. Adult Education Quarterly, 59(3), 246-263. doi:10.1177/0741713609331479

Gold, J. M. (2006). Profiling marital satisfaction among graduate students: An analysis of the perceptions of masters and doctoral students. Contemporary Family Therapy, 28, 485-495. doi:10.1007/s10591-006-9019-6

Goode, W. J. (1960). A theory of role strain. American Sociological Review, 25, 483496.

Greenhaus, J. H., \& Beutell, N. J. (1985). Sources of conflict between work and family roles. Academy of Management Review, 10(1), 76-88.

Greenhaus, J. H., \& Powell, G. N. (2007). When work and family are allies: A theory of work-family enrichment. Academy of Management Review, 31(1), 72-92.

Home, A. M. (1997). Learning the hard way: Role strain, stress, role demands, and support in multiple-role women students. Journal of Social Work Education, 33(2), 335347 .

Home, A. M. (1998). Predicting role conflict, overload and contagion in adult women university students with families and jobs. Adult Education Quarterly, 48(2), 85-97. 
Janssen, E., McBride, K. R., Yarber, W., Hill, B. J., \& Butler, S. M. (2008). Factors that influence sexual arousal in men: A focus group study. Archives of Sexual Behavior, 37, 252-265. doi:10.1007/s10508-007-9245-5

Kirby, P. G., Biever, J. L., Martinez, I., \& Gomez, J. P. (2004). Adults returning to school: The impact on family and work. Journal of Psychology, 138(1), 65-76.

Lawrance, K., \& Byers, E. S. (1998). Interpersonal Exchange Model of Sexual Satisfaction Questionnaire. In C. M. Davis, W. L. Yarber, R. Bauremen, G. Schreer, \& S. L. Davis (Eds.), Sexuality-related measures: A compendium (2nd ed., pp. 514-519). Thousand Oaks, CA: Sage.

Michel, J. S., Kotrba, L. M., Mitchelson, J. K., Clark, M. A., \& Baltes, B. B. (2011). Antecedents of work-family conflict: A meta-analytic review. Journal of Organizational Behavior, 32, 689-725. doi:10.1002/job.695

Mullen, J., Kelley, E., \& Kelloway, E. K. (2008). Health and well-being outcomes of the work-family interface. In K. Korabik, D. S. Lero, \& D. L. Whitehead (Eds.), Handbook of work-family integration: Research, theory, and best practices (pp. 191-214). San Diego, CA: Elsevier.

Murray, S. H., \& Milhausen, R. R. (2012). Sexual desire and relationship duration in young men and women. Journal of Sex and Marital Therapy, 38, 28-40.

O’Leary, M. P., Fowler, F. J., Lenderking, W. R., Barber, B., Sagnier, P. P., Guess, H. A., \& Barry, M. J. (1995). A brief male sexual function inventory for urology. Urology, 46, $697-706$.

Quimby, J. L., \& O’Brien, K. M. (2006). Predictors of well-being among nontraditional female students with children. Journal of Counseling and Development, 84(4), 451-460.

Røsand, G. B., Slinning, K., Eberhard-Gran, M., Røysamb, E., \& Tambs, K. (2012). The buffering effect of relationship satisfaction on emotional distress in couples. BioMed Central Public Health, 12, 1-14.

Rosen, R., Brown, C., Heiman, J., Leiblum, S., Meston, C., Shabsign, R., . . D’agostino, R. (2000). The Female Sexual Function Index (FSFI): A multidimensional self-report instrument for the assessment of female sexual function. Journal of Sex and Marital Therapy, 26, 191-208.

Statistics Canada. (2013). Labour force survey. Retrieved from http://search1.odesi. $\mathrm{ca} /$

Sweet, S., \& Moen, P. (2007). Integrating educational careers in work and family: Women's return to school and family life quality. Community, Work \& Family, 1O(2), 231-250. doi:10.1080/13668800701270166

van Rhijn, T. M. (2009). School-family conflict and enrichment in undergraduate student parents (Unpublished master's dissertation). University of Guelph, Guelph, ON.

van Rhijn, T. M. (2012). Post-secondary students with children: An investigation of motivation and the experiences of "student parents" (Unpublished doctoral dissertation). University of Guelph, Guelph, ON. Retrieved from https://atrium.lib.uoguelph.ca/xmlui/ handle/10214/3968 
van Rhijn, T. M., Smit Quosai, T., \& Lero, D. S. (2011). A profile of undergraduate student parents in Canada. Canadian Journal of Higher Education, 41(3), 59-80.

Voydanoff, P. (2005). Work demands and work-to-family and family-to-work conflict: Direct and indirect relationships. Journal of Family Issues, 26(6), 707-726. doi:10.1177/0192513x05277516

Whitton, S. W., \& Whisman, M. A. (2010). Relationship satisfaction instability and depression. Journal of Family Psychology, 24(6), 791-794. doi:10.1037/a0021734

Yousefi, F., Mansor, M. B., Juhari, R. B., Redzuan, M., \& Talib, M. A. (2010). The relationship between gender, age, depression and academic achievement. Current Research in Psychology, 1(1), 61-66.

\section{Contact Information}

Tricia van Rhijn

Department of Family Relations and Applied Nutrition

University of Guelph

tvanrhij@uoguelph.ca

Tricia van Rhijn is an assistant professor of family relations and human development in the Department of Family Relations and Applied Nutrition at the University of Guelph. Her research interests include parent-child relationships, child development, early childhood education and care, well-being, family relations, various aspects of work-life integration (as well as school-life or school-work-life integration), and the experiences of non-traditional students in formal postsecondary education, in particular mature students and student parents.

Sarah Hunter Murray is an individual, couples, and family therapist in Winnipeg, Manitoba, and a member of the American Association of Marriage and Family Therapists. She specializes in working with clients regarding issues related to intimacy and sexuality. Her research interests focus on gaining a better understanding of sexual desire, sexual satisfaction, and relationship satisfaction in men and women, primarily in the context of longer-term relationships.

Robert C. Mizzi is an assistant professor in the Department of Educational Administration, Foundations and Psychology at the University of Manitoba. His research interests include sexual and gender diversity in education and community; educational policy, politics, and professionalism; and transnational mobility concerns among education professionals. 